\title{
Perception of the Mentor-Mentee System among Medical Students of the Faculty of Medicine And Health Sciences, Universiti Malaysia Sarawak
}

\section{Cheah Whye Lian', Nan Ommar ${ }^{2}$, Joanne Tan Sze Fern ${ }^{3}$, Surizi Ismail ${ }^{3}$, Tengku Sarah Tengku Mohd Sharifudin ${ }^{3}$, Wong Syn Hwan ${ }^{3}$}

${ }^{1}$ Department of Community Medicine \& Public Health, Faculty of Medicine \& Health Sciences; ${ }^{2}$ Department of Basic Medical Sciences, Faculty of Medicine \& Health Sciences; ${ }^{3}$ Faculty of Medicine \& Health Sciences

\section{ARTICLE INFO}

Received

: 01/07/2012

Accepted : :25/09/2012

Published : :01/06/2013

\section{KEYWORD}

Mentor-mentee system

Pre-clinical students

Clinical students

Medical school

\begin{abstract}
Objective: To determine the perception of medical students towards mentor-mentee system in Faculty of Medicine and Health Sciences of UNIMAS. Method: It was a cross-sectional study involving all 104 second year and 80 fifth year medical students. A self-administered questionnaire consisting of socio-demographic details, general perceptions on mentormentee system, academic support, personal development, and emotional and psychological support was distributed. The data was analysed using the SPSS version 19. Result: Majority of the subjects had a positive outlook towards the mentor-mentee system with a range of $45.6 \%$ to $57 \%$. Three of the top rated perceptions were 'mentor analyses mentee's examination results and provides constructive feedback', 'mentor advises how to improve academic performance', and 'mentor gives encouragement and support for the challenges faced' $(66.8 \%, 68.0 \%$ and $62.9 \%$ respectively). Pre-cinical medical students had significantly better perception on mentormentee system than clinical students $(p \leq 0.002)$ while those with nonclinician mentors significantly had better perceptions than those with clinician mentors $(p \leq 0.003)$ on the system. No significant difference was found between the perceptions of males and females for all components ( $p=0.234$ to 0.722 ). Conclusion: The mentor-mentee system was found to be successful as more than half of the respondents had posititve perception on the system and its aspects. However, pre-clinical students benefited more compared to clinical students, which reflects the need to look at the support given to clinical students. It was recommended that future studies should incorporate the perceptions of mentors.
\end{abstract}

(C) Medical Education Department, School of Medical Sciences, Universiti Sains Malaysia. All rights reserved.

CORRESPONDING AUTHOR: Dr Cheah Whye Lian Department of Community Medicine \& Health Sciences, Faculty of Medicine \& Health Sciences, Universiti Malaysia Sarawak, Lot 77, Section 22 KTLD, Jalan Tun Ahmad Zaidi Adruce, 93150 Kuching, Sarawak. Email: wlcheah@fmhs.unimas.my 


\section{Introduction}

Mentoring is described as a fundamental form of human development where one person invests time, energy, and personal knowledge in assisting the growth and ability of another person (1). In medical teaching, mentoring plays a vital role in supporting students for career guidance, as well as personal development (2), and is regarded as one of the most important influences on the development of health professionals in academic medicine (3). Being a medical student in a medical school is perceived by the society as an accomplishment but in most of the cases the students have to undergo a lot of challenges to succeed. Studies on wellness of medical students showed that many of them suffered from emotional exhaustion, depersonalization and have low sense of personal accomplishment. All these have negative impact on the performance, competency, professionalism and health of students (4). Some medical students even consumed alcohol to handle anxiety, stress and pressure, and 8-25\% had suicidal thoughts (5). A good mentoring system helps the mentee to establish oneself quickly in the new learning and social environments, gain requisite knowledge and skills, and develop the right and appropriate attitudes and behavior, thus promoting the socialization, development and maturation in medicine (6-7). However, an unclear or wrongly written guideline on mentor-mentor system creates negative impacts which in return causes mentees' lack of enthusiasm to meet their mentors (8). Therefore it is important that a mutual understanding between mentor and mentee is established.

Faculty of Medicine and Health Sciences (FMHS), University Malaysia Sarawak (UNIMAS) have implemented a mentor-mentee system as the guiding and educating methodology in its undergraduate curriculum since its first student intake in 1995/1996. Under this program, students as mentees are assigned to academic staff during a given period of their studies. It is a common practice for the faculty to assign non-clinicians for pre-clinical students and clinicians for clinical students; however, clinicians are also assigned to pre-clinical students based on the availability of clinicians. The objectives of FMHS's mentor-mentee system are to promote and help students in academic and professional development; develop positive attitude and self image, good communication and public relation skills; provide positive role models; expand the mentee's horizon and vision; provide advice, counsel and supports; and listen to and share ideas and give feedback. Mentors play an important role in assisting their mentees in problem-solving besides advising them on academic matters. They also provide feedback for reflective review following the release of End-of-Block (EOB) and End-of-Posting (EOP) results. On the other hand, mentees are responsible to meet up with their mentors to discuss their learning progress including any academic difficulties encountered. All mentees are provided with a log book and log card to enable them to record the frequency and purpose of meetings made with their respective mentors. The first mentor-mentee meeting is planned to take place during the second week after new students have joined the medical program. Thereafter, subsequent meetings should either occur at the beginning of each course or whenever necessarily. Guidelines on the mentormentee meeting schedule and activities are provided in the log book. Despite the vital roles of mentors and the well-defined purposes of mentor-mentee system in Faculty of Medicine and Health Sciences, UNIMAS, it is still a challenge to know what is required by mentees from their mentors. Since its implementation, there is no evaluation on the impact of the mentoring system being formally done. Furthermore, past studies had indicated students at different stages need different mentoring approach and student's gender can affect mentoring preference. By understanding the needs of mentees, a well-tailored mentoring program would contribute more to the success of mentoring. This study was aimed to assess the perception of mentees about this program. It is hoped that the findings from this study will provide information to improve the mentoring program. 


\section{Method}

It was a cross-sectional study done on the medical students of UNIMAS during a period of three months between September to November 2011. A total of 104 second year medical students and 80 fifth year students were recruited. Second year students were selected to represent the pre-clinical years and have undergone two years of mentoring experience. Fifth year medical students, on the other hand were selected because they have been in the clinical years for almost three years and their mentoring experience should be adequate.

After giving consent, the students filled up a selfadministered questionnaire (Table 2) which consisted of socio-demographic information, perceptions on the mentor-mentee system, mentor support in personal development, academic, emotional and psychological matters. Except for socio-demographic information, scores were generated for each component using a five points Likert scale (1=strongly disagree, $2=$ disagree, $3=$ neutral, 4=agree and 5=strongly agree). High scores indicate better perceptions. There were five statements asked under perception on the mentor-mentee system, four statements under academic support, seven statements under personal development, and seven statements under emotional and psychological support. A pilot test on the questionnaire was conducted with overall Cronbach's alpha of 0.67 , and individual items ranged from 0.62 to 0.93 .

Statistical analyses were performed with Statistical Package for Social Sciences Program (SPSS) version 19.0. The data were coded and entered into SPSS data file for descriptive and inferential analysis. The level of significance was set at $5 \%$ (2 sided).

\section{Result}

A total of 184 medical students participated in the study. There were more female participants $(60.3 \%)$ compared to male participants $(39.7 \%)$. Among the races, the majority of participants were Chinese $(44.6 \%)$ and followed closely by
Malays (40.8\%). The rest were Indians, Ibans, Bidayuh and other races with percentages of $5.4 \%, 3.8 \%, 3.8 \%$ and $1.6 \%$ respectively. There were more non-clinician mentors $(51.6 \%)$ than clinician mentors $(47.8 \%)$.

Table 1: Socio-demographic characteristics of subject $(\mathrm{N}=184)$

\begin{tabular}{lrr}
\hline & $\mathbf{n}$ & $\mathbf{\%}$ \\
\hline Gender & & \\
Male & 73 & 39.7 \\
Female & 111 & 60.3 \\
Race & & \\
Chinese & 82 & 44.6 \\
Malay & 75 & 40.8 \\
Indian & 10 & 5.4 \\
Iban & 7 & 3.8 \\
Bidayuh & 7 & 3.8 \\
Others & 3 & 1.6 \\
Year & & \\
2nd & 104 & 56.5 \\
5th & 80 & 43.5 \\
Mentor & & \\
Clinician & 88 & 47.8 \\
Non clinician & 95 & 51.6 \\
Don't know & 1 & 0.6 \\
\hline
\end{tabular}

The majority of the subjects had a positive outlook towards the mentor-mentee system with a range of percentage from $45.6 \%$ to $57 \%$. At the sub-component level, the majority of the respondents agreed that they received academic support $(36.4 \%$ to $67.9 \%$ ). The most significant element benefited by the subjects was mentors advising them to improve their academic performance $(67.9 \%)$. The least significant element was mentors referring any resource person when necessary (36.4\%) (Table 2).

More than one third of the subjects agreed that they had gained personal development from the system $(32.1 \%$ to $50.6 \%)$. The subjects were found to agree the most on the element where their mentors stress on commitment to lifelong learning $(50.6 \%)$. In the aspect of emotional and psychological support gained from the system, majority of the respondents agreed to this with a range from $25.5 \%$ to $62.8 \%$. The respondents were most agreeable on the element that their mentors gave them encouragement and support for challenges faced (62.8\%). However, there were substantial no opinions on the elements of mentors making time for the subjects besides the regular meetings, having a friend-like 
relationship with their mentors and mentors counselling them on personal matters, mentor helps with upgrade mentee's abilities, mentor provides support in setting career goals with a percentage of $46.2 \%, 45.1 \%, 45.1 \%, 41.3 \%$ and $46.7 \%$ respectively.

Comparison between year of study, second year medical students had better perception on mentor-mentee system with a mean of $3.57(\mathrm{SD}=0.74)$ compared to fifth year students with a mean of $2.92(\mathrm{SD}=0.95)$. This difference was found to be significant $(p<0.001)$. Under the sub-components on academic support, personal development, emotional and psychological support, similar findings were found where there were significant differences between the two groups $(p<0.001)$.

Second year medical students mentees had a better perception on the mentor-mentee system with a mean of $3.57(\mathrm{SD}=0.71)$ compared to fifth year medical students whose mean scored 3.01 $(\mathrm{SD}=0.95)$. This difference was found to be significant $(p<0.001)$. At the same time, mentees with non-clinicians as mentors had better perceptions on the aspects gained from the system which comprises of academic support, personal development and emotional and psychological support as compared to mentees with clinician mentors and the differences between the two groups were significant with $p<0.001$ respectively.

In terms of comparison between males and females, there was no significant difference in all aspects.

\section{Discussion}

More than $45 \%$ of the respondents perceived the mentor-mentee system was beneficial to them. This indicated the mentor-mentee system implemented in the Faculty of Medicine and Health Sciences had achieved its objectives in improving students in terms of developing positive attitude, developing good communication skill, facing challenges, role model to follow and solving problem. The oneto-one formal mentoring approach practiced by the faculty proven to be beneficial to the mentees. A review in the literature indicated high level of satisfaction was reported among those medical students who were on one-to-one mentoring system (9-10). Nevertheless, it is challenging for most medical schools to provide such mentoring system in view of the availability of trained and experienced mentors.

At the academic support level, more than $66 \%$ of the respondents agreed that their mentors analyse examination results and provide feedback, and advice on how to improve academic performance. It is not known if the mentees meet their mentors voluntarily as this is the only way for mentees to obtain end-of-block or posting examination results in details. However, studies indicated about $90 \%$ to $95 \%$ of medical students value mentorships and regard mentoring as very important, particularly in academic development (11).

In terms of personal development support, more than $40 \%$ of the respondents agreed that mentormentee system builds confidence in them. Being away from families, students are more likely to approach their mentors for advice. The respondents also reported that their mentors stress on commitment to lifelong learning. As medical education grows more complex, doctors need to keep up-to-date evidence-based knowledge in their practice and a positive lifelong learning attitude. A good mentor who acts as a model is crucial to assist mentor in facing challenges in working environment as well as career development. This is why more than $60 \%$ of the respondents agreed that their mentors give encouragement, emotional and psychological support whenever they need. Their mentors also listen attentively and reinforce good achievement. Consistent with many studies (12-15), a proper mentoring helps the medical students to face different types of pressure, with a need to adapt to a new environment, stressful nature of medical training. Furthermore, in this country, students are admitted into undergraduate medical training when they are still just teenagers, entering young adulthood. 
However, there is also a remark finding where respondents rated as neutral or no opinion more dominantly in elements: mentor helps to upgrade mentee's abilities, mentor provides support in setting career goals, extra time the mentors spare for the mentees beside the regular meetings, friend-like relationship between mentors and mentees, trusting and feeling safe when discussing about personal matters with the mentors, and mentor's counseling the mentee on their personal problems. Based on some theoretical models of mentoring (16), mentoring needs vary according to the mentees' experience, needs and level of training. Some mentees expect their mentor to help them to handle and solve problems. Others may want their mentors in setting up career goals. A mismatch of goals, commitments, or expectations is some of the common issues that caused dissatisfaction between mentors and mentees (17). In terms of extra meetings, it is unlikely to be held as the mentors might be busy, occupied with other commitment; particularly more than $40 \%$ of the mentors in this study are clinicians who need to attend to patients in the clinics. This phenomenon is quite common. Surveys done in the United Kingdom reported many medical trainees do not always receive the stipulated minimum supervision because of the busy schedules of their mentors (18).

Dominant neutral responses for considering the mentor-mentee relationship like that of friends indicate that students' expectations on their relationships with the mentors are more toward professional relationship rather than the casual one. As indicated by Sackett (12) and Aagaard \& Hauer (19), the relationship between mentor and mentee should be maintained on a professional manner to prevent any outburst of emotion that might be difficult to handle. This was why respondents did not regard their mentors as their friends. Furthermore, age difference and the nature of the relationship indicated that most mentors see themselves in a superior position to their mentees.

Second year medical students had better perceptions on mentor-mentee system compared to fifth year medical students. This can be due to that second year medical students are less familiar with their academic surroundings as they are quite new in the faculty. According to Cramer and Prentice-Dunn (20), young adults entering college often confront a variety of social, academic and psychological challenges. Hence, pre-clinical students need more guidance from their respective mentors and tend to seek help from their mentors more often. On the other hand, fifth year students are already familiar with their academic surroundings. They do not require as much guidance and hence seek help from their mentors less often. Having mentioned that, there are many other possible factors contributing to why fifth year students did not perceive mentormentee system benefitial to them. Kilminster \& Jolly (21) argued that mentoring should be not focus purely on academic and personal development but on career development and life after medical school. This is evidenced by a study done in Switzerland where medical graduates stated that mentoring would have helped them in deciding specialty training earlier and strategized a more goal-oriented approach in planning their career (22).

Students with non-clinicians as their mentors had better perception on the mentor-mentee system than those having clinicians as their mentors. This may be because majority of clinician mentors are more occupied in hospitals and also with third year medical students which are located in another training centre far away from the faculty. This made them less available for the students. Whereas, non-clinical mentors are only occupied with pre-clinical students whom are most of the time centered in the faculty, are likely to be available. Furthermore, as indicated earlier that the needs of pre-clinical students in terms of mentoring support are more compared to clinical students. In order to overcome this, mentoring should be structured, with written contract to ensure continuity. The contract should include information on the frequency and direction of meeting, appraisal and assessment, goal setting, written requirement (16). The mentoring relationship is a dynamic one that evolves over time, where both mentor and mentee continually define and redefine their roles (23). 
In terms of gender, male and female had no significant differences in their perception on the mentor-mentee system and any of the aspects. This can be because regardless of gender, the needs of the students are still the same and that gender does not really play a significant role. Although literatures indicated race, gender, social class affect mentoring relationship but the findings were inconclusive (24).

As a conclusion, the overall findings showed that majority of mentees had positive perception on this system and benefited from this system in three aspects : academic support, personal development and emotional and psychological support. Non-clinical students were found to have a better perception on the system and also gained more from it. Hence, it can be concluded that mentoring involving non clinical students is more fruitful compared to clinical students. A change in the mentoring system should be considered in order to make sure the support for clinical students is in place, particularly on the availability of mentor for meeting with mentee.

Several limitations of this present study should be noted. The findings of this study were based on the perception of second and fifth year medical students only and may have biased the results towards a positive perception of the mentor-mentee system. Perceptions by mentees could also be investigated in greater depth, using more rigorous methods like qualitative research method (interviews or focus groups). To complete the understanding of mentor-mentee system, future studies should also include the mentors' perspectives. This could lead to clarification of some issues that were not explored in this study such as the role of mentors, the needs of mentees particularly the final year students, which may lead to a more balance perspective. Nevertheless, besides providing useful information for internal assessment, the present study's findings indicated that this kind of iniative helps to improve the planning, implementation and evaluation of mentor-mentee programme.

\section{Reference}

1. Shea GF. Making the most of being mentored: how to grow from a mentoring partnership. Menlo Park,CA: Crisp Publications, Inc. 1999.

2. Asadi H, Josephson A, Stenfors-Hayes T. Perceptions of medical students and their mentors in a specialised programme designed to provide insight into nontraditional career paths. International Journal of Medical Education. 2011;2:64-69.

3. Jefferies A, Skidmore M. Evaluation of a collaborative mentorship program in a multisite postgraduate training program. Medical Teacher. 2010;32: 695-697.

4. Rosal MC, Ockene IS, Ockene JK, Barrett SV, Ma Y, Hebert JR. A longitudinal study of students' depression at one medical school. Acad Med. 1997 Jun;72(6):542-6.

5. Dyrbye LN, Szydlo DW, Downing SM, Sloan JA, Shanafelt TD. Development and preliminary psychometric of a well-being index for medical students. BMC Medical Education. 2010 Jan 27;10:8.

6. Straus SE, Chatur F, Taylor M. Issues in the mentor-mentee relationship in academic medicine: A qualitative study. Acad Med. 2009;84:135-139.

7. Lunsford LG. Psychology of mentoring: the case of talented college students. Journal of Advanced Academics. 2011;22:474-498.

8. Taherian, K., \& Shekarchian , M. (2008). Mentoring for doctors. Do its benefits outweigh its disadvantages? Med Teac. 2008;30:95-99.

9. Frishman W. Student research projects and theses : should they be a requirement for medical school graduation? Heart Disease. 2001;3:140-144.

10. Haq C, Grosch M, Carufel-Wert D. Leadership opportunities with communities, the medically underserved, and special populations (LOCUS). Academic Medicine. 2002;77:740.

11. Ricer RE, Fox BC, Miller KE. Mentoring for medical students interested in family practice. Fam Med. 1995;27:360-365.

12. Sackett DL. On the determinants of academic success as a clinician-scientist. 
Clinical and investigative medicine. 2001;24(2):94-100.

13. Detsky AS, Baerlocker MO. Academic mentoring-how to give it and how to get it. JAMA. 2007;297(19):2134-2136.

14. Anderson W. Support, Expectations, Awareness \& Influence: Reflections on Youth and Democracy Articles. Journal of Community Psychology. 2007;35(6): 811814

15. Borisoff D. Strategies for effective mentoring and for being effectively mentored: A focus on research institutions. Journal of the Association for Communication Administration. 1998;27:84-96.

16. Buddeberg-Fischer B, Herta KD. Formal mentoring programmes for medical students and doctors - a review of the MedLine literature. Medical Teacher. 2006;28(3):248-257.

17. Zerzan JT, Hess R, Schur E, Philips RS, Rigotti N. Making the most of mentors : A guide for mentees. Academic Medicine. 2009;84(1):140-144.

18. Panayiotou BN, Fortherby MD. Junior hospital doctors' view on their training in the UK. Postgrad Med J. 1996;72:851.

19. Aagaard EM, Hauer KE. A cross-sectional descriptive study of mentoring relationships formed by medical students. J Gen Intern Med. 2003 April;18(4): 298-302.
20. Cramer RJ, Prentice-Dunn S. Caring for the whole person: Guidelines for advancing undergraduate mentorship. College Student Journal. 2007 Dec Part A;41(4):771-778.

21. Kilminster SM, Jolly BC. Effective supervision in clinical practice settings : A literature review. Medical Education. 2000;34:827-840.

22. Buddeberg-Fischer B, Stamm M, Buddeberg C. Academic career in medicinerequirements and conditions for successful advancement in Switzerland. BMC Health Serv Res. 2009;9:70.

23. Frei E, Stamm M, Buddeberg-Fischer B. Mentoring programs for medical students A review of the PubMed literature 20002008. BMC Medical Education. 2010;10:32. Available at http://www.biomedcentral.com/14726920/10/32.

24. Vonk ME, Zucrow E, Thyer BA. Female MSW students' satisfaction with practicum supervision : The effect of supervision gender. J Soc Work Educ. 1996;32(3):415419 
Table 2: Perception of respondents on mentor-mentee system $(\mathrm{N}=184)$

\begin{tabular}{lcccccc}
\hline & Strongly & Disagree & No opinion & Agree & $\begin{array}{c}\text { Strongly } \\
\text { agree }\end{array}$ \\
& disagree & $\mathbf{n}(\%)$ & $\mathbf{n}(\%)$ & $\mathbf{n}(\%)$ & $\mathbf{n}(\%)$ & $\mathbf{n}(\%)$ \\
\hline
\end{tabular}

\section{Perception on mentor-mentee}

1. This program enables me to gain support on any challenges faced.

2. This program helps me to develop a positive attitude.

3. This program provides me with positive role models.

4. This program helps me to develop good communication skill.

5. This program assists me in problem solving skills.

\section{Academic Support}

1. My mentor assists me to understand the MD curriculum.

2. My mentor refers me to a resource person when necessary.

2. My mentor refers me to a resource person when necessary.

3. My mentor analyses my examination results and provides constructive feedback for reflective review.

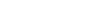

$\begin{array}{lllll}15(8.1) & 25(13.6) & 52(28.3) & 80(43.5) & 12(6.5) \\ 14(7.6) & 23(12.5) & 42(22.9) & 93(50.5) & 12(6.5) \\ 11(6.0) & 23(12.5) & 52(28.3) & 84(45.6) & 14(7.6) \\ 12(6.5) & 27(14.7) & 61(33.2) & 79(42.9) & 5(2.7) \\ 12(6.5) & 25(13.6) & 59(32.1) & 81(44.0) & 7(3.8) \\ 10(5.4) & 31(16.9) & 55(29.9) & 74(40.2) & 14(7.6) \\ 10(5.4) & 35(19.0) & 72(39.1) & 56(30.5) & 11(6.0) \\ 10(5.4) & 35(19.0) & 72(39.1) & 56(30.5) & 11(6.0) \\ 9(4.9) & 16(8.7) & 36(19.6) & 85(46.2) & 38(20.6) \\ 8(4.3) & 14(7.6) & 37(20.1) & 95(51.7) & 30(16.3)\end{array}$

performance.

\section{Personal Development}

1. My mentor helps me to upgrade my abilities (example: try a new professional activity, draft a section of an article).

2. My mentor builds confidence in me.

3. My mentor is able to identify my strengths and weaknesses.

4. My mentor provides support in setting career goals (specialty in academic medicine).

$\begin{array}{lllll}10(5.4) & 34(18.5) & 76(41.3) & 59(32.1) & 5(2.7) \\ 12(6.5) & 27(14.7) & 63(34.2) & 72(39.2) & 10(5.4) \\ 11(6.0) & 31(16.8) & 73(39.7) & 61(33.2) & 8(4.3) \\ 11(6.0) & 28(15.2) & 86(46.7) & 50(27.2) & 9(4.9) \\ 11(6.0) & 27(14.7) & 71(38.6) & 6(36.4) & 8(4.3) \\ 11(6.0) & 20(10.8) & 60(32.6) & 78(42.4) & 15(8.2) \\ 12(6.5) & 18(9.8) & 67(36.4) & 71(38.6) & 16(8.7)\end{array}$

5. My mentor helps me to self-assess through reflection.

7. My mentor is a role model to me.

\section{Emotional and psychological support}

1. My mentor gives encouragement and support for the challenges faced.

2. My mentor listens attentively to me when I discuss my difficulties.

3. My mentor reinforces my good achievements.

4. My mentor made time for me besides the regular meetings.

5. My mentor is like a friend to me.

6. My mentor is trustworthy and I feel safe discussing personal matters with him/her.

7. My mentor counsels me on my personal problems.

\begin{tabular}{lllll}
$9(4.9)$ & $20(10.9)$ & $39(21.3)$ & $102(55.3)$ & $14(7.6)$ \\
$8(4.3)$ & $12(6.5)$ & $59(32.1)$ & $87(47.3)$ & $18(9.8)$ \\
$9(4.9)$ & $12(6.5)$ & $61(33.2)$ & $90(48.9)$ & $12(6.5)$ \\
$12(6.5)$ & $24(13.1)$ & $85(46.2)$ & $54(29.3)$ & $9(4.9)$ \\
$12(6.5)$ & $30(16.3)$ & $83(45.1)$ & $49(26.1)$ & $11(6.0)$ \\
$11(6.0)$ & $27(14.7)$ & $68(36.9)$ & $62(33.7)$ & $16(8.7)$ \\
$14(7.6)$ & $40(21.7)$ & $83(45.1)$ & $42(22.8)$ & $5(2.8)$ \\
\hline
\end{tabular}


Table 3: Relationship between year, mentor, and gender of respondents with the perception of mentormentee system

\begin{tabular}{|c|c|c|c|c|}
\hline Variable & $\begin{array}{l}\text { Perception on } \\
\text { mentor-mentee } \\
\text { system }\end{array}$ & $\begin{array}{l}\text { Academic } \\
\text { support }\end{array}$ & Personal development & $\begin{array}{c}\text { Emotional and } \\
\text { psychological support }\end{array}$ \\
\hline \multicolumn{5}{|l|}{ Year $^{\mathrm{a}}$} \\
\hline 2nd & $3.57(0.74)$ & $3.68(0.74)$ & $3.40(0.71)$ & $3.42(0.68)$ \\
\hline 5th & $2.92(0.95)$ & $3.13(0.90)$ & $2.94(0.89)$ & $3.06(0.85)$ \\
\hline$p$ value & $0.000 *$ & $0.000^{*}$ & $0.000^{*}$ & $0.002 *$ \\
\hline \multicolumn{5}{|l|}{ Mentor $^{a}$} \\
\hline Clinician & $3.01(0.95)$ & $3.18(0.90)$ & $3.02(0.88)$ & $3.11(0.84)$ \\
\hline Non- clinician & $3.57(0.71)$ & $3.71(0.68)$ & $3.39(0.69)$ & $3.43(0.64)$ \\
\hline$p$ value & $0.000 *$ & $0.000 *$ & $0.002 *$ & $0.003^{*}$ \\
\hline \multicolumn{5}{|l|}{ Gender $^{\mathrm{a}}$} \\
\hline Male & $3.26(0.83)$ & $3.40(0.85)$ & $3.13(0.78)$ & $3.18(0.73)$ \\
\hline Female & $3.31(0.93)$ & $3.47(0.86)$ & $3.25(0.85)$ & $3.32(0.80)$ \\
\hline$p$ value & 0.722 & 0.619 & 0.351 & 0.234 \\
\hline
\end{tabular}

aindependent t-test, *significant at $p<0.05$ 